\title{
Recent Arctic amplification and extreme mid-latitude weather
}

\author{
Judah Cohen ${ }^{1 \star}$, James A. Screen ${ }^{2}$, Jason C. Furtado1, Mathew Barlow ${ }^{3,4}$, David Whittleston ${ }^{5}$, \\ Dim Coumou ${ }^{6}$, Jennifer Francis ${ }^{7}, K^{2}$ laus Dethloff ${ }^{8}$, Dara Entekhabi ${ }^{5}$, James Overland ${ }^{9}$ and Justin Jones ${ }^{1}$
}

\begin{abstract}
The Arctic region has warmed more than twice as fast as the global average - a phenomenon known as Arctic amplification. The rapid Arctic warming has contributed to dramatic melting of Arctic sea ice and spring snow cover, at a pace greater than that simulated by climate models. These profound changes to the Arctic system have coincided with a period of ostensibly more frequent extreme weather events across the Northern Hemisphere mid-latitudes, including severe winters. The possibility of a link between Arctic change and mid-latitude weather has spurred research activities that reveal three potential dynamical pathways linking Arctic amplification to mid-latitude weather: changes in storm tracks, the jet stream, and planetary waves and their associated energy propagation. Through changes in these key atmospheric features, it is possible, in principle, for sea ice and snow cover to jointly influence mid-latitude weather. However, because of incomplete knowledge of how high-latitude climate change influences these phenomena, combined with sparse and short data records, and imperfect models, large uncertainties regarding the magnitude of such an influence remain. We conclude that improved process understanding, sustained and additional Arctic observations, and better coordinated modelling studies will be needed to advance our understanding of the influences on mid-latitude weather and extreme events.
\end{abstract}

T he Arctic cryosphere is an integral part of Earth's climate system and has undergone unprecedented changes within the past few decades. Rapid warming and sea-ice loss has had significant impacts locally, particularly in late summer and early autumn. September sea ice has declined at a rate of $12.4 \%$ per decade since 1979 (ref. 1), so that by summer 2012, nearly half of the areal coverage had disappeared. This decrease in ice extent has been accompanied by an approximately $1.8 \mathrm{~m}(40 \%)$ decrease in mean winter ice thickness since 1980 (ref. 2) and a 75-80\% loss in volume ${ }^{3}$.

Though sea-ice loss has received most of the research and media attention, snow cover in spring and summer has decreased at an even greater rate than sea ice. June snow cover alone has decreased at nearly double the rate of September sea ice ${ }^{4}$. The decrease in spring snow cover has contributed to both the rise in warm season surface temperatures over the Northern Hemisphere extratropical landmasses and the decrease in summer Arctic sea ice ${ }^{5}$. The combined rapid loss of sea ice and snow cover in the spring and summer has played a role in amplifying Arctic warming. However, snow cover and sea-ice trends diverge in the autumn and winter with sea ice decreasing in all months while snow cover has exhibited a neutral to positive trend in autumn and winter ${ }^{6}$.

\section{Climate change and Arctic amplification}

While the global-mean surface temperature has unequivocally risen over the instrumental record ${ }^{7}$, spatial heterogeneity of this warming plays an important role in the resulting climate impacts. In particular, the near-surface of the Northern Hemisphere high latitudes are warming at rates double that of lower latitudes ${ }^{8-10}$. This observed phenomenon (Figs 1 and 2a,b) is termed polar or Arctic amplification. Arctic amplification occurs in all seasons, but is strongest in autumn and winter. It is also a consistent feature in coupled climate model simulations of the recent past and future projections forced with increased greenhouse-gas concentrations ${ }^{11,12}$. Several processes are thought to contribute to Arctic amplification, including local radiative effects from increased greenhouse-gas forcing ${ }^{12,13}$, changes in the snow- and ice-albedo feedback induced by a diminishing cryosphere ${ }^{14-16}$, aerosol concentration changes and deposits of black carbon on snow and ice surfaces ${ }^{17}$, changes in Arctic cloud cover and water vapour content ${ }^{18,19}$, and a relatively smaller increase in emission of longwave radiation to space in the Arctic compared with the tropics for the same temperature increase ${ }^{20}$. In addition to these local drivers of Arctic amplification, Arctic temperature change is sensitive to variations in the poleward transport of heat and moisture into the Arctic from lower latitudes ${ }^{16,21}$.

Rapid Arctic warming has been accompanied by extensive loss of sea ice. ${ }^{9}$ Arctic sea ice strongly modulates near-surface conditions at high latitudes, which then influences regional and, potentially, remote climate. Because open water has a much lower albedo than ice, more sunlight is absorbed at the ocean surface, where sea ice has recently receded in the Arctic. More absorbed energy has resulted in $4-5{ }^{\circ} \mathrm{C}$ sea surface temperature anomalies in these newly ice-free regions ${ }^{22}$. However, during autumn when the air cools to temperatures lower than the ocean surface, the excess heat absorbed during summer is transferred from the ocean to the atmosphere via radiative and turbulent fluxes, which strongly warms the lower Arctic troposphere. The additional heat in the system slows the formation

\footnotetext{
${ }^{1}$ Atmospheric and Environmental Research, Inc., Lexington, Massachusetts 02421, USA, ${ }^{2}$ College of Engineering, Mathematics and Physical Sciences, University of Exeter, Exeter, Devon EX4 4QF, UK, ${ }^{3}$ Department of Environmental, Earth, and Atmospheric Sciences, University of Massachusetts Lowell, Lowell, Massachusetts 01854, USA, ${ }^{4}$ The Climate Change Initiative, University of Massachusetts Lowell, Lowell, Massachusetts 01854, USA, ${ }^{5}$ Department of Civil and Environmental Engineering, Massachusetts Institute of Technology, Cambridge, Massachusetts, 02139, USA, ${ }^{6}$ Potsdam Institute for Climate Impact Research - Earth System Analysis, 14412 Potsdam, Germany, ${ }^{7}$ Institute for Marine and Coastal Sciences, Rutgers University, New Brunswick, New Jersey 08901, USA, ${ }^{8}$ Alfred Wegener Institute, Helmholtz Centre for Polar and Marine Research, AWI Potsdam 14473, Germany, ${ }^{9}$ Pacific Marine Environmental Laboratory, Seattle, Washington 98115, USA. *e-mail: jcohen@aer.com
} 

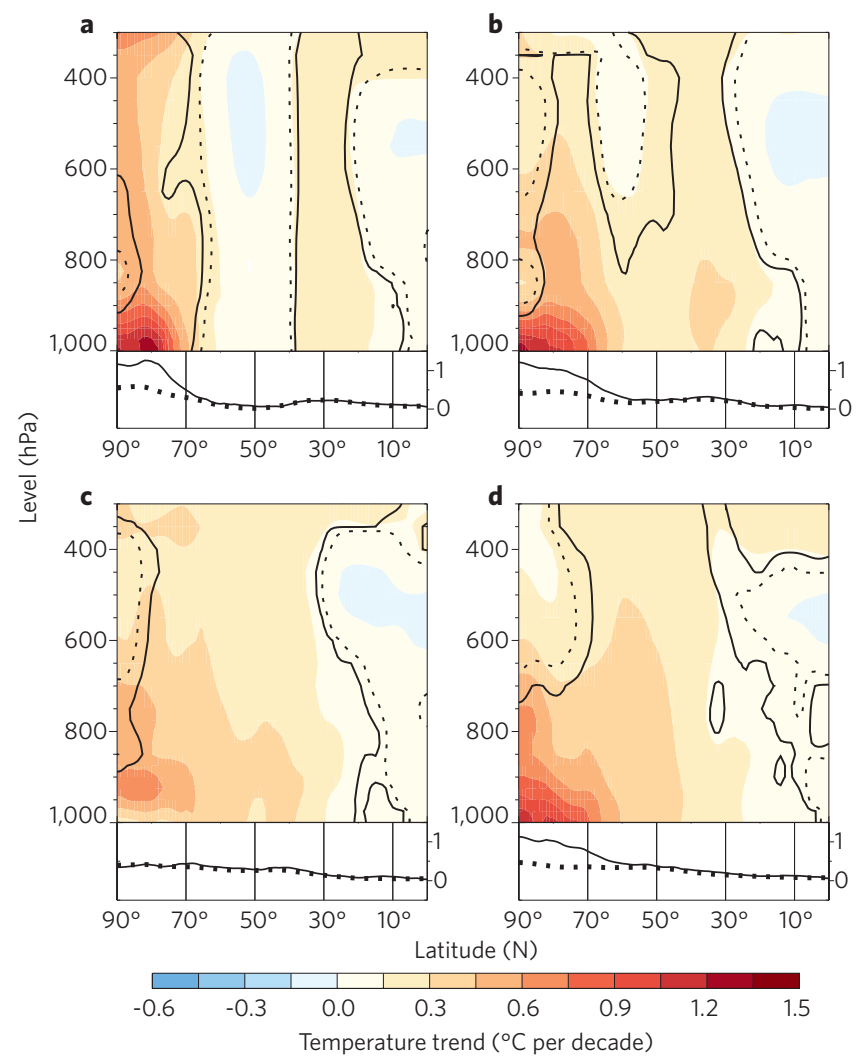

Figure 1 | Polar amplification of temperature trends, 1979-2014. Zonally

averaged temperature trends averaged around circles of latitude for a, winter (December-February), b, spring (March-May), c, summer (June-August) and $\mathbf{d}$, autumn (September-November). Trends are based on ERA-Interim reanalysis data ${ }^{95}$ from March 1979 to February 2014. The black contours indicate where trends differ significantly from zero at the $99 \%$ (solid lines) and 95\% (dotted lines) confidence levels. The line graphs show trends (same units as in colour plots) averaged over the lower part of the atmosphere (950-1,000 hPa; solid lines) and over the entire atmospheric column (300-1,000 hPa; dotted lines) 9 .

of sea ice through winter, both in extent and, especially, thickness $^{23,24}$. Hence, winter sea ice has thinned ${ }^{2}$, enabling easier melting, fracturing and/or mobility of the ice cover. The increased fraction of open water in winter generates warmer, moister air masses over the Arctic Ocean and nearby continents ${ }^{15,25}$, weakening the meridional near-surface temperature gradient. Therefore, these feedbacks indicate that observed Arctic sea-ice loss acts as both a response to and a driver of Arctic amplification.

\section{Mid-latitude extreme weather}

A large number of extreme heat and rainfall events have been reported over the past decade, especially in the Northern Hemisphere mid-latitudes ${ }^{26-31}$. Figure 3 illustrates that several standard extreme temperature and precipitation indices have increased in frequency and intensity over mid-latitude land areas $\left(20-50^{\circ} \mathrm{N}\right)$ with especially rapid changes since the 1990s. For example, the amount of precipitation on very wet days (exceeding the 95th percentile) has increased from 160 to $185 \mathrm{~mm}$, and the percentage of warm days (exceeding the 90th percentile) has increased from 10\% before 1980 to $16 \%$ at present ${ }^{32}$.

Extreme weather has not been limited to heavy rainfall and warm temperatures and recently has included cold extremes as well. Winter temperatures have generally warmed since 1960 (Fig. 2a), and the frequency of anomalously cold winter days has decreased over mid-tohigh latitudes, but primarily north of $50^{\circ} \mathrm{N}$, since 1979 in response to mean warming and decreased variability ${ }^{33}$. However, also evident in Fig. 3d,f is that the number of days continuously below freezing has increased and the minimum temperatures have decreased since 1990. Figure $3 \mathrm{~h}$ also indicates that the frequency of unusually cold winter months (colder than two standard deviations below the 1951-1980 mean $^{30}$ ) had reversed its longer-term downward trend by the end of the 1990s. This trend reversal in cold extremes has coincided with an acceleration in the rate of warming at high latitudes relative to the rest of the Northern Hemisphere starting approximately in 1990 (Fig. 2b). As seen in Fig. 2c, continental winter temperature trends since 1990 exhibit cooling over the mid-latitudes, replacing the warming trends observed over the longer period since 1960 (Fig. 2a). The winter temperature trends shown in Fig. 2c start in 1990 but are not sensitive to the exact start date. However, on average, daily winter cold extremes were less severe over this period than they have been historically ${ }^{33}$. The rapid Arctic warming implies that cold air outbreaks, when Arctic air moves south into the mid-latitudes, are becoming less severe ${ }^{33}$.

The seven years between 2007 and 2013 have exhibited the lowest minimum sea-ice extents recorded in September since satellite observations began, with an all-time record low in 2007 followed by another in 2012, when sea-ice extent fell below 4 million $\mathrm{km}^{2}$ for the first time in the observational record. Several of these seven winters following the low sea-ice minima have been unusually cold across the Northern Hemisphere extratropical landmasses ${ }^{34-38}$. The recent winter of 2013-2014 was characterized by record cold and widespread snowstorms across the eastern United States and Canada with the most intense cold-air outbreak in decades associated with the weakening of the polar vortex ${ }^{39}$. The persistent and harsh cold resulted in all-time record cold winters around the Great Lakes of the United States since record keeping began in the 1870 s.

The media and public have been quick to make the connection between global, and in particular Arctic, warming and extreme weather ${ }^{40}$. While global warming theory is consistent with record warm temperatures and more intense precipitation events, it does not directly explain cold extremes. Coupled models project boreal winter amplification under greenhouse-gas forcing, where the Northern Hemisphere landmasses would warm faster in winter relative to the other seasons $s^{11,41}$. Warming in the Arctic has continued unabated since at least 1960. Longer-term observed temperature trends in mid-latitudes are consistent with these projections, while shorter-term trends are not. This highlights that results are sensitive to the spatial extent of the analysis, the exact definition used and especially the duration of an extreme, as extremes of differing durations may be driven by different physical processes.

While cold extremes may be mostly due to natural variability, a growing number of recent studies argue that recent extreme winter weather is related to Arctic amplification. Three possible dynamical pathways through which Arctic amplification may influence midlatitude weather, including extreme weather, are summarized below. We focus our discussion on Arctic linkages to mid-latitude weather in the winter season for two reasons. First, most studies that have linked Arctic amplification to mid-latitude weather have focused on winter (a brief discussion of proposed linkages in other seasons, mainly summer, is provided in the Supplementary Information). Second, winter is the season in which mid-latitude temperature trends have diverged most notably from both model projections and from the other seasons ${ }^{42}$. To provide a focused review, we limit our consideration to the literature concerning recent past (midtwentieth century onwards) and present-day climate variability and trends. The implications of projected future Arctic amplification (for example, at the end of the twenty-first century) are likely large and wide ranging, but are not considered here.

\section{Arctic amplification influences and uncertainties}

Whether to attribute severe winter weather to Arctic amplification or natural variability has emerged as a major debate among 
a
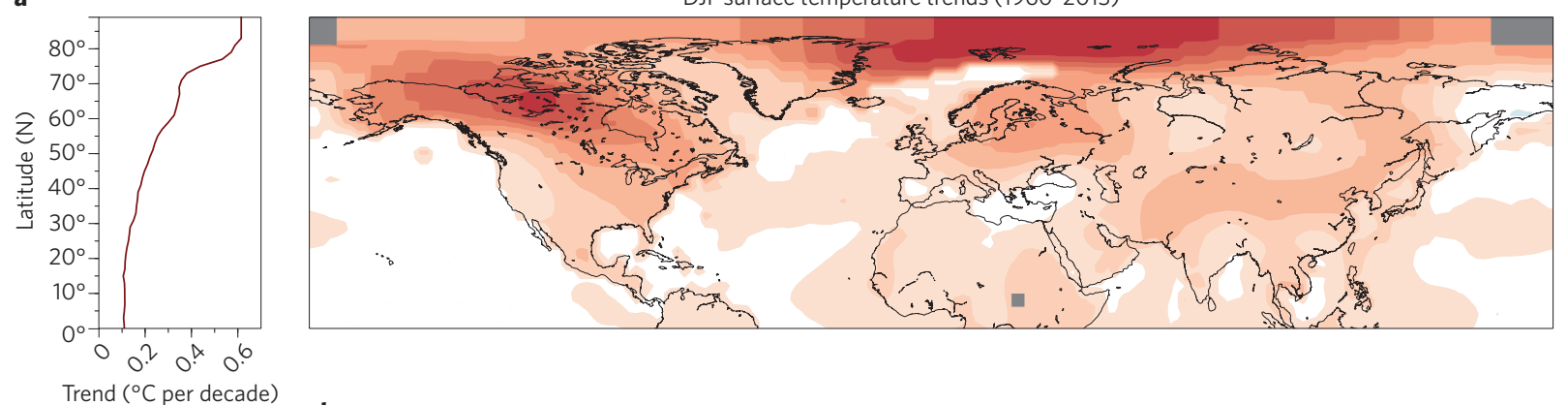

DJF surface temperature trends (1960-2013)

b

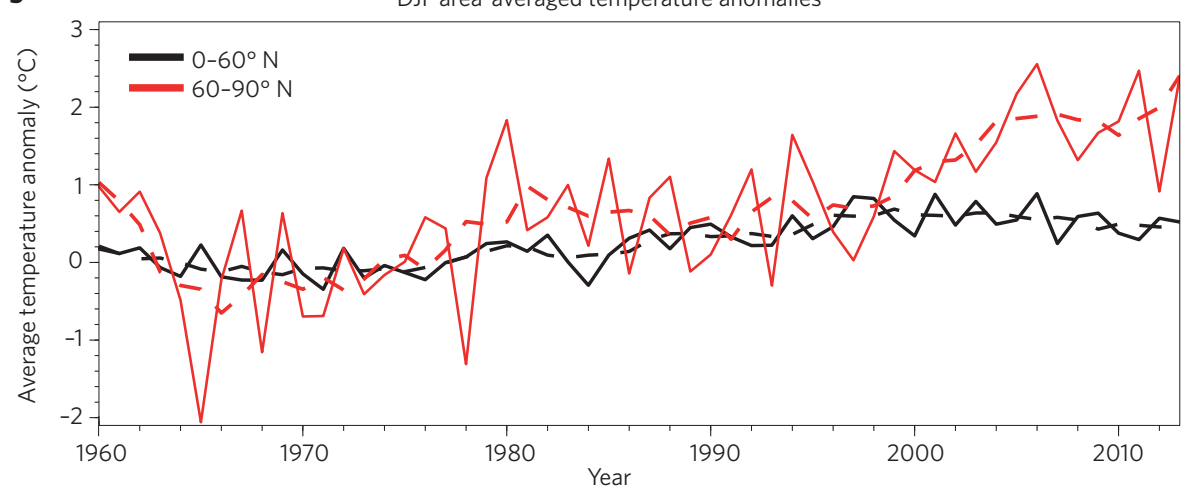

C
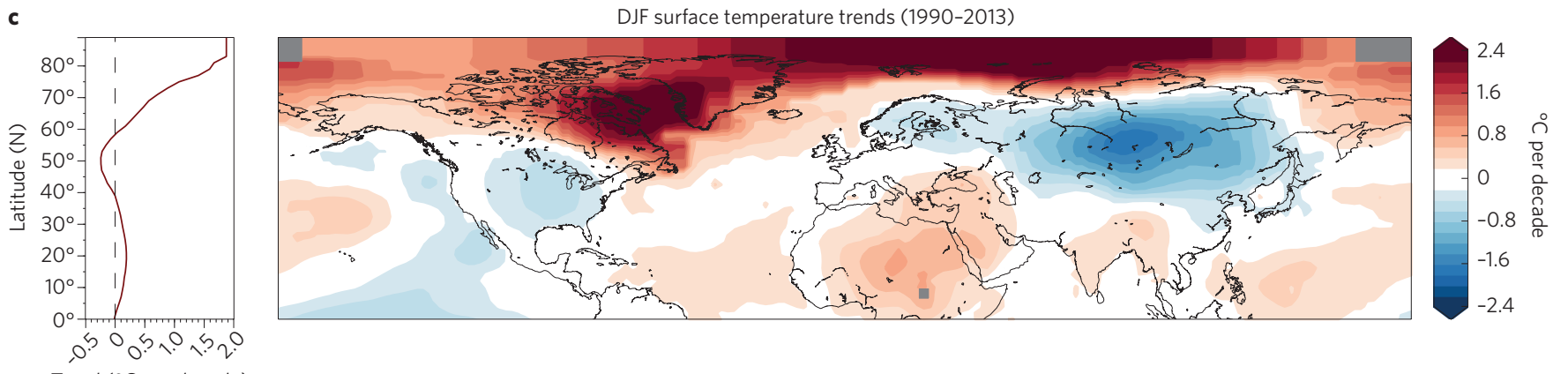

Figure 2 | Winter temperature trends since 1960 and over the most recent period from 1990. a, Right: linear trend $\left({ }^{\circ} \mathrm{C}\right.$ per 10 years) in DecemberFebruary (DJF) mean surface air temperatures from 1960-1961 to 2013-2014. Shading interval every $0.1^{\circ} \mathrm{C}$ per 10 years. Dark grey indicates points with insufficient samples to calculate a trend. Left: The zonally averaged linear trend $\left({ }^{\circ} \mathrm{C}\right.$ per 10 years). $\mathbf{b}$, Area-average surface temperature anomalies $\left({ }^{\circ} \mathrm{C}\right.$ ) from $0^{\circ}$ to $60^{\circ} \mathrm{N}$ (solid black line) and $60^{\circ}$ to $90^{\circ} \mathrm{N}$ (solid red line) along with five-year smoothing (dashed black and red lines, respectively). c, As in panel a but from $1960-1961$ to $2013-2014$. Shading interval every $0.2^{\circ} \mathrm{C}$ per 10 years. Also note different scales between $\mathbf{a}$ and $\mathbf{c}$. Data from the National Aeronautics and Space Administration Goddard Institute for Space Studies temperature analysis (http://data.giss.nasa.gov/gistemp) ${ }^{96}$.

scientists $^{43-45}$. In the observations, Arctic amplification has separated from the noise of natural variability only in the past approximately two decades (Fig. 2b), presenting a challenge for the detection of robust atmospheric responses to Arctic amplification, including mid-latitude weather, over such a short time period. In addition to the relatively short length of the observational record, the Arctic is poorly sampled. A major caveat of any observational study is that correlation alone cannot demonstrate a causal link. Cause and effect can be established through sensitivity or perturbation studies using climate models, but models are subject to their own deficiencies. Known model errors include sea-ice-atmosphere coupling ${ }^{46,47}$, energy fluxes and cloud properties $^{47}$. Furthermore, modelling studies of the effects of sea-ice loss on large-scale atmospheric circulation have produced conflicting results that make interpretation difficult. Finally, our understanding of fundamental driving forces of mid-latitude weather is incomplete ${ }^{48}$.

Given these sources of uncertainty, a consensus on whether and how Arctic amplification is influencing mid-latitude weather is lacking. To facilitate advancement on this important issue, therefore, we synthesize key findings that argue for and against a significant link between Arctic amplification and mid-latitude weather. All studies agree that the first order impact of sea-ice melt is to modify the boundary layer in the Arctic ${ }^{15,25}$. However, if and how that signal propagates out of the Arctic to mid-latitudes differs and can be loosely grouped under three broad dynamical frameworks: (1) changes in storm tracks mainly in the North Atlantic sector; (2) changes in the characteristics of the jet stream; and (3) regional changes in the tropospheric circulation that trigger anomalous planetary wave configurations. In Fig. 4, we show the known primary influences on mid-latitude weather, including the three dynamical pathways introduced above and described in more detail in the following sections. We recognize that these three pathways are not distinct as they involve dynamical features of the atmospheric circulation that are highly interconnected. Whilst imperfect, our choice of this separation reflects the different dynamical frameworks that are commonly used - if not explicitly acknowledged to study the dynamics of mid-latitude weather. 
a

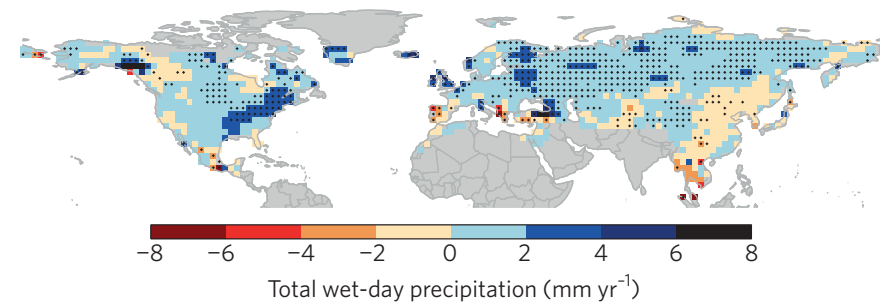

c
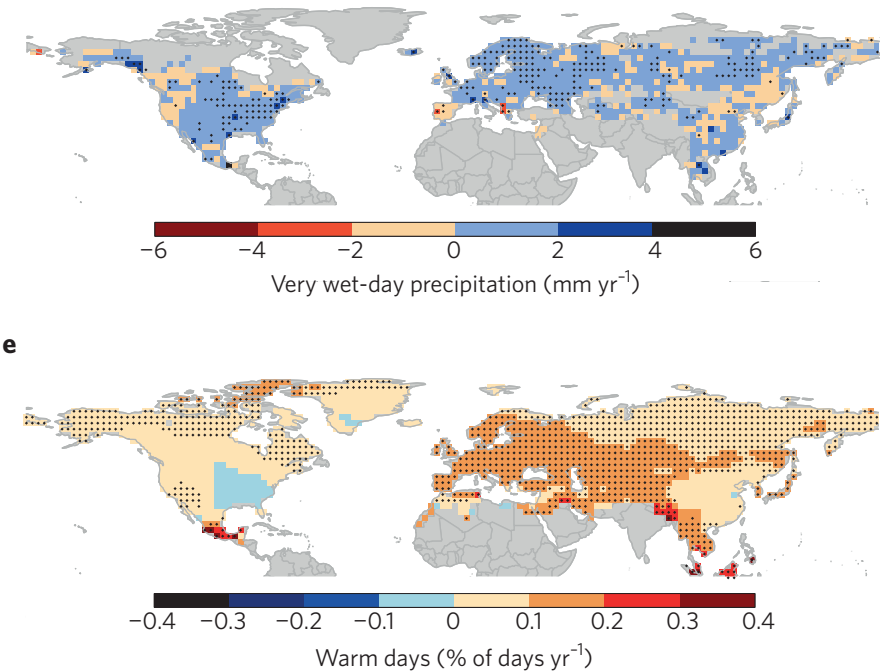

g

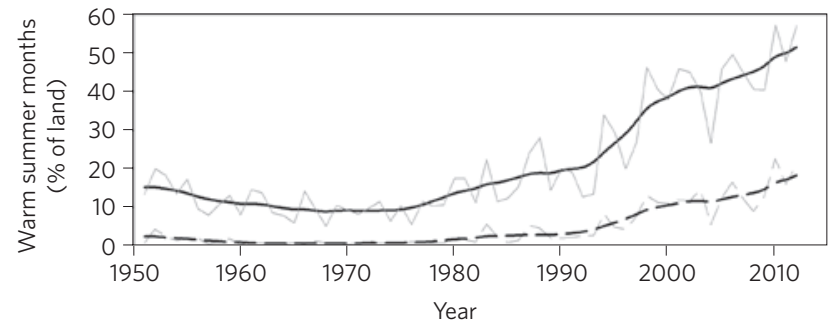

b

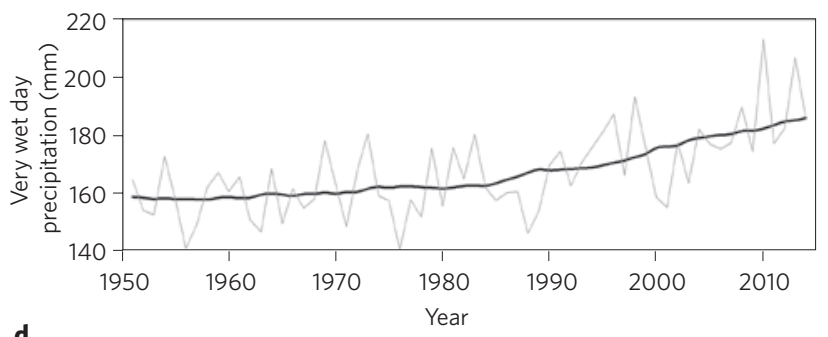

d

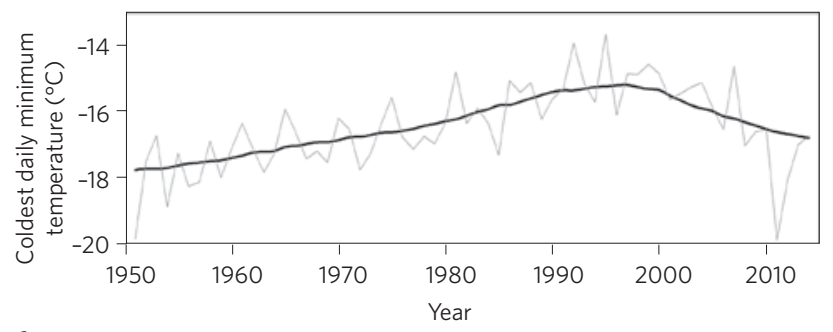

f

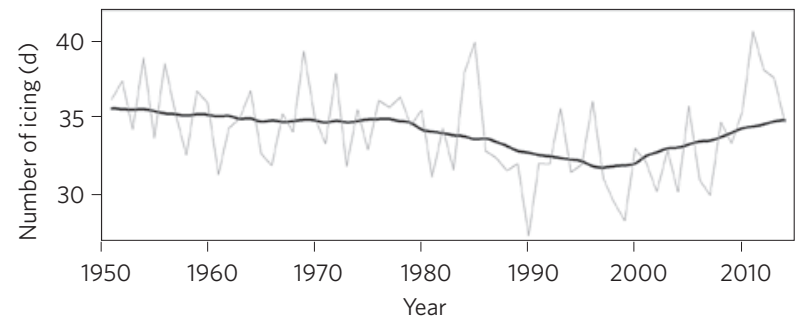

h

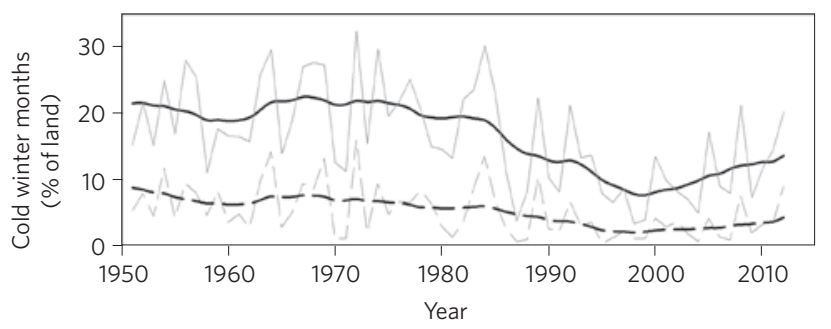

Figure 3 | Temperature and precipitation extremes. Extreme indices in the mid-latitudes: trend maps for the 1951-2013 period and time series averaged over the land area from $20^{\circ}$ to $50^{\circ} \mathrm{N}$. a, Trend in annual total wet-day precipitation. $\mathbf{b}$, Annual very wet-day precipitation (that is, precipitation during days exceeding the 95th percentile). c, Trend in annual very wet-day precipitation (that is, precipitation during days exceeding the 95th percentile). d, Coldest daily minimum temperature. e, Trend in annual warm days (that is, percentage of days with temperatures exceeding the 90 th percentile). $\mathbf{f}$, Annual number of icing days (days with maximum temperature $<0^{\circ} \mathrm{C}$ ). $\mathbf{g}$, Percentage of land with summer months warmer than one standard deviation (solid) and two standard deviations (dashed) above the 1951-1980 mean. h, Percentage of land with winter months colder than one standard deviation (solid) and two standard deviations (dashed) below the 1951-1980 mean ${ }^{30}$. Stippling in the trend maps indicates significance at 95\% confidence. The time series plot yearly values (thin grey curves) and the long-term nonlinear trend (thick black curves). Panels a-f were created using the GHCNDEX global land gridded dataset of climate extremes ${ }^{32}$ and definition of the extreme indices ${ }^{32}$.

\section{Storm tracks}

Large-scale and low-frequency variability in the extratropical atmosphere is dominated by shifts in storm tracks, often expressed by changes in large-scale atmospheric modes ${ }^{49}$. The dominant atmospheric or climate mode that explains the greatest percentage of the mid- to high-latitude atmospheric variability, including changes in the storm tracks, is the North Atlantic Oscillation/Arctic Oscillation (NAO/AO). Changes in the storm tracks associated with the NAO/AO have a strong influence on the surface temperature and precipitation variability in the North Atlantic sector ${ }^{50}$. When the NAO/AO is in its positive phase, the storm tracks shift poleward and winters are predominately mild across northern Eurasia and the eastern United States but cold in the Arctic. When the NAO/AO is in its negative phase, the storm tracks shift equatorward and winters are predominantly more severe across northern Eurasia and the eastern United States, but relatively mild in the Arctic. This temperature pattern is sometimes referred to as the 'warm Arctic-cold continents' pattern $^{51}$. Recent observed wintertime temperature trends across the Northern Hemisphere continents (Fig. 2c) project strongly on this temperature-anomaly pattern ${ }^{37}$, reflecting a negative trend in the NAO/AO over the past two decades ${ }^{37}$. Given that climate models forced by regional and latitudinal variations in atmospheric heating also exhibit changes in the $\mathrm{NAO} / \mathrm{AO}^{50,52}$, it is plausible that variability in sea ice and/or snow cover can influence the phase and amplitude of the $\mathrm{NAO} / \mathrm{AO}$, and consequently the storm tracks.

The temperature pattern associated with variations in Eurasian snow cover projects strongly onto the temperature pattern associated with the NAO/AO and recent temperature trends ${ }^{34,37,53}$. October snow cover anomalies across Eurasia have been proposed as a skilful 


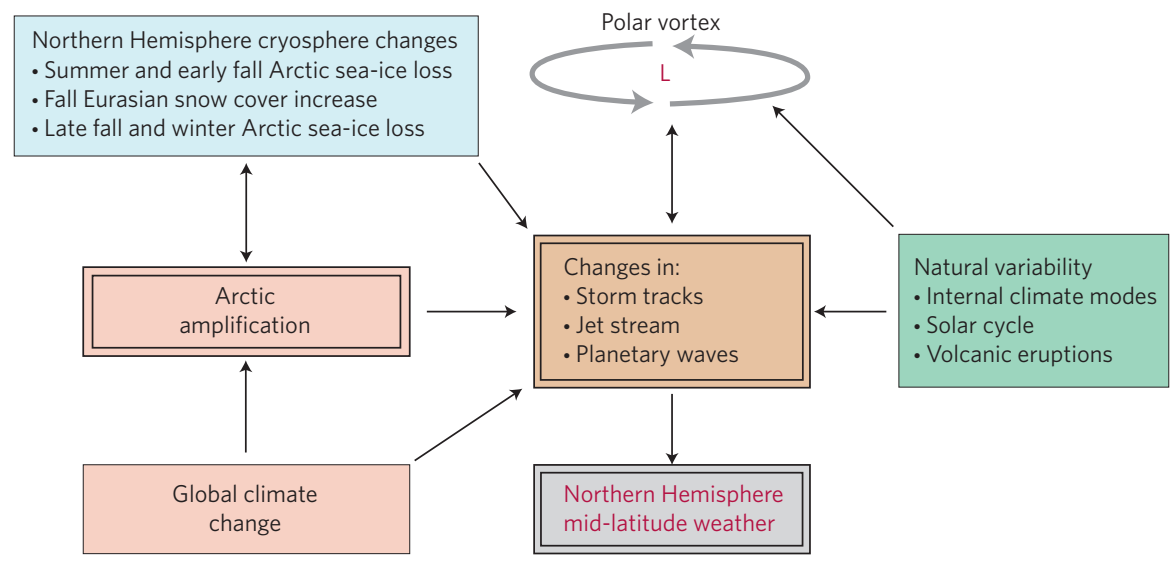

Figure 4 | Schematic of ways to influence Northern Hemisphere mid-latitude weather. Three major dynamical features for changing Northern Hemisphere mid-latitude weather - changes in the storm tracks, the position and structure of the jet stream, and planetary wave activity - can be altered in several ways. The pathway on the left and highlighted by double boxes is reviewed in this manuscript. Arctic amplification directly (by changing the meridional temperature gradient) and/or indirectly (through feedbacks with changes in the cryosphere) alters tropospheric wave activity and the jet stream in the mid- and high latitudes. Two other causes of changes in the storm tracks, jet stream and wave activity that do not involve Arctic amplification are also presented: (1) natural modes of variability and (2) the direct influence of global climate change (that is, including influences outside the Arctic) on the general circulation. The last two causes together present the current null hypothesis in the state of the science against which the influence of Arctic amplification on mid-latitude weather is tested in both observational and modelling studies. Bidirectional arrows in the figure denote feedbacks (positive or negative) between adjacent elements. Stratospheric polar vortex is represented by ' $L$ ' with anticlockwise flow.

predictor of the winter $\mathrm{NAO} / \mathrm{AO}^{54,55}$, where extensive snow cover is associated with the negative phase of the $\mathrm{NAO} / \mathrm{AO}$, though the relationship may lack stationarity ${ }^{56}$. Satellite-based data indicate a positive trend in Eurasian snow cover during October over the past two to three decades ${ }^{6,37}$, though the veracity of these satellitebased increases has recently been questioned ${ }^{57}$. A proposed physical mechanism to explain increased snow cover is that a warmer Arctic atmosphere can hold more water vapour, which enhances precipitation over the Eurasian continent. Additionally, the loss of sea ice - and thus the increase in open water - has increased moisture fluxes to the atmosphere ${ }^{9}$. If near-surface atmospheric temperatures remain sufficiently cold - as is the case in Siberia during autumn and winter - any additional precipitation will likely occur as snow ${ }^{58,59}$. Therefore, increasing October Eurasian snow cover may have contributed to the recent tendency towards a negative $\mathrm{NAO} / \mathrm{AO}$ and cold Northern Hemisphere winters ${ }^{37}$. However, given that the $\mathrm{NAO} / \mathrm{AO}$ has considerable internal variability on multiple timescales, the recent negative trend may be predominantly internally driven.

The strong decline in sea ice during recent decades has intensified interest in the interactions between sea-ice conditions and the atmosphere ${ }^{47,60}$. Most sea-ice-atmosphere coupled studies have discussed the atmospheric response in the context of NAO/AO variability. Observational analyses have shown significant correlation between reduced Arctic sea-ice cover and the negative phase of the winter $\mathrm{NAO} / \mathrm{AO}^{35,37,61-64}$, although it is unclear whether late summer and early autumn ${ }^{35}$ or late autumn and early winter ${ }^{38}$ sea-ice anomalies are more skilful at predicting the winter weather patterns.

Modelling studies have also examined the NAO/AO response to variations in Arctic sea ice ${ }^{35,65-74}$, by running simulations forced by past sea-ice trends or case studies of years with large sea-ice anomalies. These studies have shown a full spectrum of NAO/AO responses to reduced sea ice, from shifts toward the positive phase ${ }^{68,71,73}$, the negative phase $\mathrm{s}^{35,65,74}$ or no significant change $\mathrm{e}^{73}$.

Furthermore, attributing NAO/AO changes and associated shifts in storm tracks to Arctic forcing has proved very difficult. The simulated atmospheric circulation response to sea-ice loss is sensitive to differences in model physics, background atmospheric and oceanic states, and the spatial patterns and magnitude of sea-ice anomalies.
Additionally, it has proven difficult to separate forced change due to sea-ice loss from internal model variability. Large numbers of model runs or ensembles are likely required to achieve statistically significant responses to forced sea-ice changes ${ }^{73}$. While these disparities between studies preclude definitive conclusions, two general results emerge. First, there are more studies that show a negative NAO/AO response than a positive $\mathrm{NAO} / \mathrm{AO}$ response. Second, the simulated $\mathrm{NAO} / \mathrm{AO}$ response to sea-ice loss is relatively small compared with natural variability. This is consistent with the view that changes in the $\mathrm{NAO} / \mathrm{AO}$ are predominately internally driven and do not necessarily require remote forcing ${ }^{75}$.

\section{Jet stream}

The second proposed dynamical pathway linking Arctic amplification to increased weather extremes is through its effects on the behaviour of the polar jet stream. The difference in temperature between the Arctic and mid-latitudes is a fundamental driver of the polar jet stream; therefore, a reduced poleward temperature difference could result in a weaker zonal jet with larger meanders. A weaker and more meandering flow may cause weather systems to travel eastward more slowly and thus, all other things being equal, Arctic amplification could lead to more persistent weather patterns ${ }^{76}$. Furthermore, Arctic amplification causes the thickness of atmospheric layers to increase more to the north, such that the peaks of atmospheric ridges may elongate northward and, thus, increase the north-south amplitude of the flow ${ }^{76}$. Weather extremes frequently occur when atmospheric circulation patterns are persistent, which tends to occur with a strong meridional wind component ${ }^{77,78}$.

Some aspects of this hypothesized linkage are supported by observations and model simulations. A significant decrease in zonal-mean zonal wind at $500 \mathrm{hPa}$ during autumn is observed regionally ${ }^{76,79}$. This may be understood through the thermal wind relationship, which states that vertical wind shear is proportional to the meridional temperature gradient. Assuming that the winds do not increase at the surface, the zonal wind at the jet-stream level should slacken with a weaker meridional temperature gradient. In other seasons when Arctic amplification is weaker, no significant trend in zonal-mean zonal wind is observed. 
However, challenges remain in linking Arctic amplification directly to changes in the speed and structure of the jet stream. For example, other factors besides the near-surface meridional temperature gradient influence the zonal jet, including feedbacks from synoptic eddies or storms and the upper-level meridional temperature gradient. Indeed, although Arctic amplification has weakened the near-surface meridional temperature gradient, the temperature gradient between the tropics and mid-latitudes at higher altitudes has strengthened ${ }^{80}$, which would increase jet stream-level winds. Another challenge is identifying how much of the Arctic

\section{Box 1 | Jet-related dynamics.}

The different components of a generalized mid-latitude jet are illustrated in Fig. B1a. The proposed dynamical pathways linking Arctic amplification to increased weather extremes are through the highly nonlinear interaction between the jet stream, the planetary waves and the storm tracks (Fig. 4). The wintertime extratropical climate variability is affected by a complex set of interactions and feedbacks between components, such as natural variability modes, diabatic heating anomalies due to variations in sea ice and snow cover, and atmospheric and oceanic heat transport from tropical and subtropical latitudes. However, recently it has been proposed that air-sea interaction in the Arctic could be forcing teleconnection patterns and influencing weather patterns remotely in the mid-latitudes by heating the Arctic relative to the rest of the globe ${ }^{36,76}$.

A change in the meridional temperature gradient, which projects onto the thermally driven component of the jet may or may not result in a significant change in the jet depending on how the eddy-driven part of the jet varies. Complex interactions between the mid-latitude wind jets, the planetary waves and baroclinic weather systems is a nonlinear two-way feedback process, where diabatic heating and cooling, orographic forcing and eddy wave breakings drive the jets and teleconnection patterns. The yellow arrow denotes the final influence, which is of synoptic variability (jet eddies) on mid-latitude weather. The dynamical mechanisms associated with each green arrow are as follows:

A. The temperature gradient, in this definition, influences the thermally driven jet (black solid circle) via the thermal-wind balance (in combination with boundary conditions).

B. The temperature gradient influences the eddy-driven jet (black dashed circle) via changes in baroclinicity. The eddy-driven jet influences the temperature gradient via horizontal heat fluxes.

C. The eddy-driven jet affects stratospheric winds (black U shape) via vertical wave propagation. Stratospheric winds affect the eddy-driven jet by altering the vertical wave-guide.
D. The thermally driven jet affects stratospheric winds via generation of orographically forced waves. Stratospheric winds affect the thermally driven jet by altering the vertical wave guide.

E. The thermally driven jet affects the eddy-driven jet by acting as a wave guide (the role of baroclinicity here directly associated with the temperature gradient). The eddy-driven jet affects the thermally driven jet via energy fluxes.

As can be seen from the figure, there are many feedbacks and interactions involving mid-latitude jets, with the temperature gradient being just one of them. Therefore a weakening in the temperature gradient may or may not result in a slowing down of the jet depending on the net effect of other factors.

The North Atlantic Oscillation/Arctic Oscillation (NAO/AO) may be considered a paradigm for the debate within the climate community. Shown in Fig. B1b are the changes in the atmospheric circulation associated with the negative phase of the NAO/AO. Positive (negative) zonal wind anomalies associated with the negative NAO/AO are superimposed on the jet shown by a green solid (dashed) line. Also shown are the temperature changes with warmer temperatures in the Arctic (red) and colder temperatures in the mid-latitudes (blue), increased high-latitude blocking (represented by clockwise flow around a high) and a southward shift in the storm tracks (represented by a anticlockwise flow around a low), and increased meridional flow. All these dynamical changes are observed as the NAO/AO shifts from its positive phase to the negative phase. However, external forcing, such as a reduced thermal gradient due to Arctic amplification, will project onto these dynamical patterns associated with the negative NAO/AO: an equatorward shift in the zonal jet, increased meridional flow, high-latitude blocking and a southward shift in storm tracks. The yellow broken arrow denotes uncertainty whether a change in the meridional temperature gradient can force all the other changes depicted in the figure. Attributing observed changes in mid-latitude weather to either Arctic amplification or internal variability has proven challenging to date.

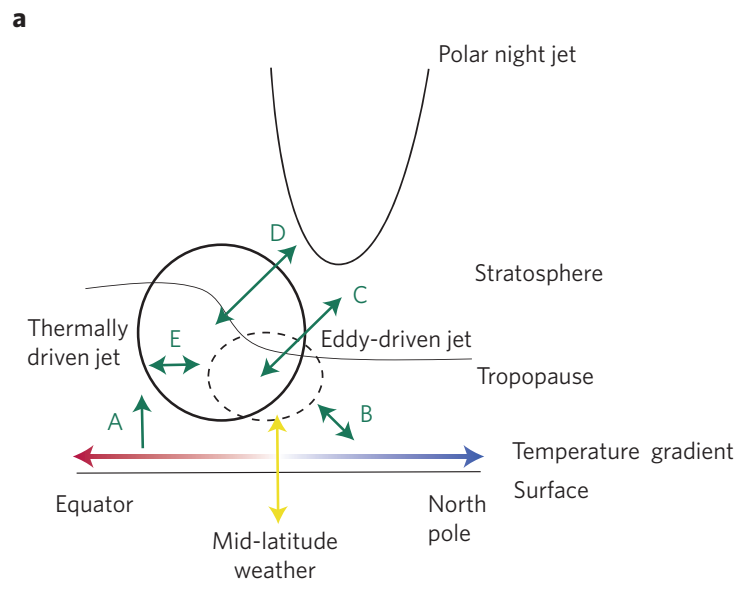

b

Figure B1 | Schematic view of jet-related and negative North Atlantic Oscillation/Arctic Oscillation dynamics. a, Here, the tropospheric jet is divided into two parts, a thermally driven part and an eddy-driven part. $\mathbf{b}$, Changes in the atmospheric circulation associated with the negative phase of the North Atlantic Oscillation/Arctic Oscillation. See Box text for detailed explanation. 
amplification is driven by local changes compared with remote changes ${ }^{16}$. This distinction is highly relevant to the current debate on possible Arctic-mid-latitude linkages, because if a significant portion of Arctic amplification is driven remotely, then Arctic amplification may be partly viewed as a response to rather than a forcing of mid-latitude weather. This highlights the importance of

\section{Box 2 | Synthesis of cryospheric forcings.}

As a summary of the studies presented, in Fig. B2 we synthesize some common ideas about the atmospheric response to sea-ice and snow cover variability that have until now been treated independently. All sea-ice studies agree that sea-ice loss heats and moistens the boundary layer of the Arctic atmosphere. It has also been shown that a surface heat source in the extratropics induces downward descent of air over the heat source, warming the atmospheric column and raising heights in the mid-troposphere, while a trough develops downstream inducing an equatorward flow of cold air ${ }^{97}$. This is consistent with the result that reduced sea ice favours an increase in mid-tropospheric heights in the Barents and Kara seas region in winter ${ }^{51,88,92}$ with downstream troughing over Eurasia. Studies also agree that increased snow cover cools the boundary layer ${ }^{54}$. Therefore a snow-induced surface cooling can lower heights in the mid-troposphere, inducing enhanced ridging upstream.

In September and October, sea-ice loss has been most pronounced in the Chukchi and East Siberian seas. Warming of the atmosphere due to increased heating from newly ice-free ocean causes geopotential heights to increase in the mid-troposphere, which suppresses the jet stream southward over east Siberia. This pattern, referred to as the Arctic Dipole, has strengthened during the era of sea-ice loss ${ }^{61}$. A southward shift in the storm tracks over East Asia allows for a more rapid advance of Eurasian snow cover in October. Enlarged areas of open water north of Siberia also provide increased moisture flux to the atmosphere, which precipitates as snow as the air mass is advected southward over Siberia ${ }^{58,71}$ (left globe in Fig. B2).

In October, a more extensive snow cover cools the surface leading to lower heights and a trough in the mid-troposphere. Increased troughing over East Asia favours upstream ridging near the Barents and Kara seas and the Urals. Concurrently, the large sea-ice deficits and the associated strong surface heating anomalies migrate from the Chukchi and East Siberian seas in September and October to the Barents and Kara seas in November and December. This favours mid-tropospheric ridging in the Barents and Kara seas region with downstream troughing over East Asia. Therefore, the extensive snow cover over Siberia in October and November and the sea-ice loss over the Barents and Kara seas in November and December produce same-signed mid-tropospheric geopotential height patterns over Eurasia. This planetary wave configuration is favourable for increased vertical propagation of Rossby waves from the troposphere into the stratosphere ${ }^{98-100}$ (middle globe in Fig. B2).

Increased vertical propagation of Rossby wave energy from the troposphere to the stratosphere weakens the polar vortex, resulting in a stratospheric warming event. Circulation anomalies associated with the warming event appear first in the stratosphere and subsequently appear in the troposphere in January and February. These circulation anomalies resemble those associated with the negative phase of the NAO/AO; that is, ridging over the Arctic especially near Greenland, and a weaker, equatorward-shifted polar jet stream. As a result, warmer conditions prevail in the Arctic regions, but colder and more severe winter weather occurs across the mid-latitude continents with a greater likelihood of snowstorms in the population centres of the Northern Hemisphere mid-latitudes (right globe in Fig. B2).

We propose a chain of events where less sea ice and increased open water in the Arctic (that heats the atmosphere) and more snow cover (that cools the atmosphere) both force the same pattern, which results in a weakened polar vortex. Because the heating anomalies are displaced longitudinally, extensive Eurasian snow cover and reduced Arctic sea ice can constructively interfere to weaken the polar vortex and hence influence surface weather.
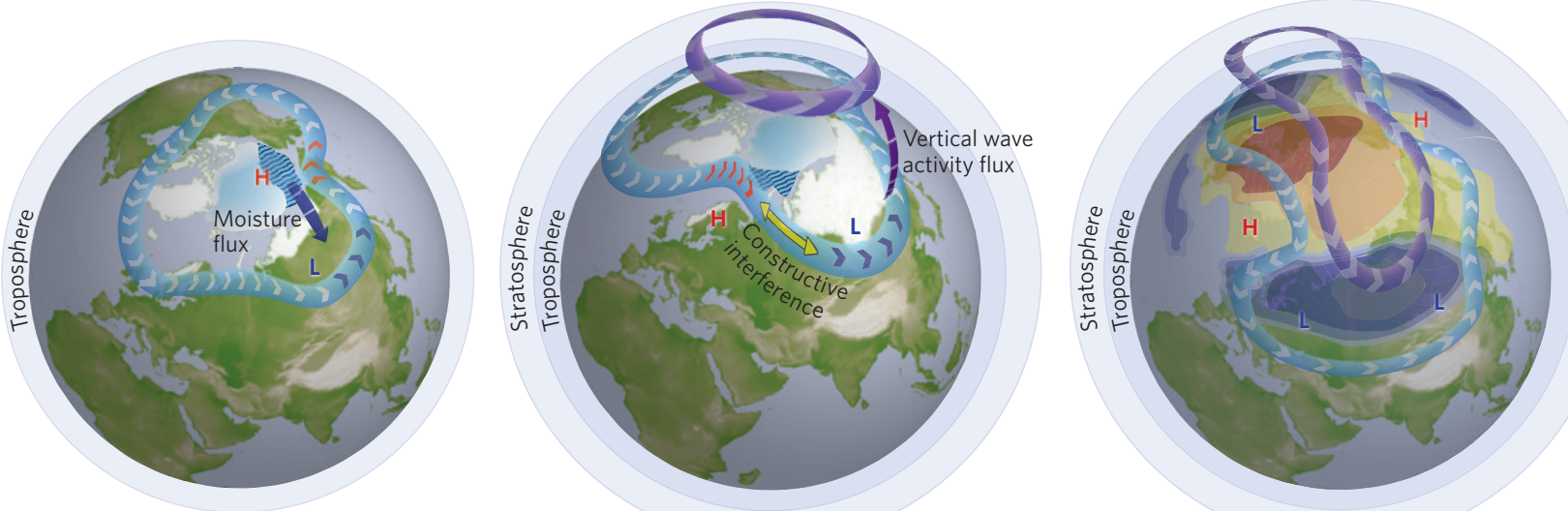

Sept. Oct. Nov. Dec Jan

Figure B2 | Synthesis of proposed cryospheric forcings. The schematic highlights a proposed way in which Arctic sea-ice loss in late summer through early winter may work in concert with extensive Eurasian snow cover in the autumn to force the negative phase of the NAO/AO in winter. Snow is shown in white, sea ice in white tinged with blue, sea-ice melt with blue waves, high and low geopotential heights with red 'H' (red represents anomalous warmth) and blue 'L' (blue represents anomalous cold) respectively, tropospheric jet stream in light blue with arrows, and stratospheric jet or polar vortex shown in purple with arrows. On the right globe, cold (warm) surface temperature anomalies associated with the negative phase of the winter $\mathrm{NAO} / \mathrm{AO}$ are shown in blue (brown). See Box text for detailed explanation. 
considering the many ways in which mid-latitude jets are influenced, including the meridional temperature gradient, which are shown schematically in Fig. B1 in Box 1.

Observational support for the follow-on impacts of the hypothesis related to a weakening zonal component of the jet ${ }^{76}$ is even less strong - namely, whether Arctic amplification leads to larger amplitude waves, slower wave propagation speeds and more persistent weather patterns. Statistically robust evidence of increasing north-south wave amplitude and slower propagation speed has not been established ${ }^{79,81}$. This is not surprising given the recent emergence of Arctic amplification and the large natural variability of the atmosphere. Recent studies provide tentative evidence for increasing amplitude in summer and autumn for some definitions of wave amplitude, but not for others ${ }^{81}$. A significant reduction in $500 \mathrm{hPa}$ wave speeds during autumn was reported ${ }^{79}$, but the response was not apparent in higher-level winds. The frequency of blockinghigh patterns is metric, region and time dependent, but as a whole the observations do not support a significant increase in blocking occurrence over recent decades ${ }^{82}$.

The theory that Arctic amplification is resulting in a slower zonal jet, increased meridional flow, amplified waves and more persistent extreme weather has received a lot of attention from the media, policymakers and climate sceintists ${ }^{83}$. In part due to the high profile, this hypothesis has been scrutinized in the scientific literature more extensively than other hypotheses linking Arctic climate change to mid-latitude weather. However, it is worth noting that other studies on related topics, especially other observational studies, share some of the same shortcomings ${ }^{35,37,38,61-64}$ (lack of statistical significance, causality unclear, incomplete mechanistic understanding, and so on).

\section{Planetary waves}

Modification to large-scale Rossby waves over Eurasia is the third proposed dynamical pathway linking Arctic amplification to midlatitude weather. Both observational analyses and modelling experiments link more extensive snow cover across Eurasia, especially in October, to changes in wave structure at high latitudes. Extensive snow cover may lead to larger planetary waves that increase the vertical propagation of wave energy into the stratosphere, favouring a warmer and weakened stratospheric polar vortex ${ }^{84-87}$. It is proposed that the atmospheric response lags the snow cover changes by a few months because of the response time of the stratospheric circulation and subsequent feedback to the troposphere.

Observed reductions in autumn-winter Arctic sea ice, especially in the Barents and Kara seas, are also correlated with strengthened anticyclonic circulation anomalies over the Arctic Ocean, which tend to induce easterly flow and cold air advection over northern Europe $^{38,88-90}$, a link that may be sensitive to the timing of the seaice anomalies. Winter anomalies trigger an immediate, local and direct atmospheric response forced by increased turbulent heat fluxes locally over the Barents and Kara seas, which in turn changes the baroclinicity and affects large-scale planetary or Rossby waves in the atmosphere. Alternatively autumn sea-ice anomalies may force a delayed, remote and indirect atmospheric response through increased Eurasian snow cover ${ }^{46}$ or through altered baroclinicity and high pressure over the Barents and Kara seas that force upward propagating planetary waves into the stratosphere. Sufficient wave breaking in the polar stratosphere weakens the stratospheric polar vortex and can trigger a stratospheric warming event. The circulation anomalies associated with a stratospheric warming event propagate back down to the surface in subsequent weeks, contributing to a persistent negative $\mathrm{NAO} / \mathrm{AO}$ and cold continental conditions ${ }^{90,91}$.

Several modelling studies have used prescribed Barents and Kara sea-ice reductions to examine how the atmosphere responds. Horizontal downstream propagation of the energy away from anomalous, sea-ice-induced high pressure over the Barents and
Kara seas leads to the formation of a trough over Eurasia and subsequent cold continental temperatures ${ }^{92}$. Such model experiments have thus far only included the impact of sea-ice changes and not the full extent of Arctic amplification.

The proposed response of planetary waves to reductions in both snow cover and sea ice has inherent shortcomings. Free-running (that is, without prescribed forcing) climate models do not simulate well observations of the amplitude or the timing of wave changes to more extensive snow cover ${ }^{86}$, resulting in a simulated weak relationship found between October Eurasian snow cover and the winter $\mathrm{NAO} / \mathrm{AO}^{93}$. Regarding the response to sea-ice loss, caution is urged, because strong trends in the sea-ice extent have made analyses of the co-variability between sea ice and the atmosphere difficult to interpret ${ }^{46}$. Furthermore the proposed atmospheric response to sea-ice forcing is not robust and has yet to achieve statistical significance $^{46}$, in part due to the shortness of the data record.

To conclude, variability in both sea ice and snow cover have been hypothesized to independently force anomalously high geopotential heights in the Barents and Kara seas. In Fig. B2 in Box 2, we provide a complementary perspective by proposing a synthesis of how extensive snow cover and reduced sea ice in the autumn and early winter can force local changes that constructively interfere to force the same response in the planetary waves, which could influence winter weather patterns.

\section{Synthesis of Arctic and mid-latitude linkages}

Dramatic changes are occurring in the Arctic climate system, and at the same time, the frequency of mid-latitude extreme weather events appears to have increased. The potential link between Arctic amplification and changes in extreme weather is a critical one, especially as Arctic amplification is robustly predicted to continue over the coming decades. The climate dynamics literature concerning Arctic-mid-latitude linkages is currently inconclusive, which may help explain the media portrayal of a polarized view among scientists $^{81}$. Furthermore, the severe winter of 2013-2014 across eastern North America focused the debate of whether extreme cold events are attributable to climate change, including Arctic amplification, or natural variability ${ }^{43,44}$. Cold winters such as the one experienced in 2013-2014 have occurred before and are expected as part of normal weather variability even on a warmer planet ${ }^{94}$. Preliminary evidence for a link between Arctic amplification and continental weather has been presented, along with a range of dynamical hypotheses for such a link. However, evidence demonstrating no robust statistical or dynamical link between Arctic amplification and mid-latitude climate variability has also been presented.

Nevertheless, dramatic changes to high-latitude sea ice and snow cover have occurred, along with profound impacts at least locally in the Arctic. The most robust atmospheric response to these changes is an altered near-surface climate in the Arctic region. There is consensus that sea-ice loss enhances local warming, which weakens near-surface meridional temperature gradients, moistens the boundary layer and decreases the near-surface static stability. A growing body of observational, modelling and theoretical evidence suggests that the impact of high-latitude surface heating increases upper-level geopotential heights, which affects the large-scale atmospheric circulation beyond the Arctic.

To the first order, amplified warming in the Arctic and a decrease in the meridional temperature gradient should favour a weaker zonal jet. However, whether weaker upper-level zonal winds causes amplified and slower-moving planetary waves remains unclear. Further evidence from modelling studies suggests that cryospheric anomalies can alter the stratospheric polar vortex, storm tracks and jet stream - all of which are key drivers of mid-latitude weather and extremes. These changes appear to be more likely in winter than other seasons owing to the large Arctic amplification signal and divergence of winter temperature trends from the other seasons. 
The link between reduced Arctic sea ice and cold continental winters is currently the most studied and arguably the best-supported link between Arctic amplification and mid-latitude extreme weather patterns.

Based on the research conducted to date, we offer a brief perspective on the challenges and research opportunities in the near future (a more detailed list is included in the Supplementary Information). Understanding the relative importance of different forcings mechanisms, and how they interact with internally generated variability, remains a key challenge. More and better observations (for example, of ocean-ice-atmosphere energy exchange, cloud cover and troposphere-stratosphere coupling) would not only improve our understanding of the Arctic and its climate, but also help to elucidate the mechanisms of atmospheric response to Arctic amplification and better constrain the models. Better standardization of metrics (extremes, blocking, wave amplitude, and so on) and coordination of modelling experiments would allow results to be more directly compared and the current disparities to be better understood. Finally, testing hypotheses in a hierarchy of models of increasing complexity, from simple dynamical models to state-of-the-art Earth system models, would help to further our understanding and better equip us to untangle the complexity of Arctic-mid-latitude linkages.

\section{Methods}

For Fig. 1, we used the monthly mean fields from the ERA-Interim reanalysis ${ }^{95}$ to compute seasonal means for the period March 1979 to February 2014. These data were averaged around circles of latitude (at $1.5^{\circ}$ resolution). Standard seasonal means were computed and used. We estimated trends using least-squares linear regression. The statistical significances of the regressions were calculated from a two-tailed $t$-test.

Surface temperature anomalies for Fig. 2 were taken from the NASA Goddard Institute for Space Studies temperature record ${ }^{96}$. The decadal linear trends in surface air temperature anomalies in Fig. 2a are based on a least-squares regression of the December-February (DJF) mean of monthly mean temperature anomalies from 1960-1961 to 2013-2014. The corresponding time series of DJF temperatures anomalies (Fig. 2b) was constructed by weighting the anomalies by the cosine of latitude. The same convention is used for Fig. 2c except that the linear trends were calculated based on DJF values during the period 1990-1991 to 2013-2014.

Figure $3 \mathrm{a}-\mathrm{f}$ was created using the GHCNDEX global land gridded dataset of climate extremes ${ }^{32}$ available at www.climdex.org. The online data-visualization tool was used to create linear trend maps and time series (over the period 1951-2014) for different extreme indices provided in the GHCNDEX global land gridded dataset. Time series are area-weighted averages of land regions within the latitudinal belt from $20^{\circ}$ to $50^{\circ} \mathrm{N}$. Figure $3 \mathrm{~g}$, h shows the percentage of land in the midlatitudes with unusually warm summer months or unusually cold winter month ${ }^{30}$. For this, we used monthly gridded data from the NASA Goddard Institute for Space Studies surface temperature dataset with a base period of 1951-1980. First, we determined the local standard deviation due to natural variability at each grid point in the latitudinal belt from $20^{\circ}$ to $50^{\circ} \mathrm{N}$ for each calendar month of the boreal winter (December-January-February) and boreal summer (June-July-August) seasons. To do so, we applied a singular spectrum analysis to extract the long-term (periods of 30 years or greater) nonlinear trend over the twentieth century. Next, we detrended the original time series by subtracting the long-term trend, which gives the year-to-year variability. From this detrended signal, monthly standard deviations were calculated using the 1951-2010 period, which were then seasonally averaged. For boreal summer, we determined the percentage of land with temperatures warmer than one and two standard deviations beyond the mean (Fig. 3g). For boreal winter, we determined the percentage of land with temperatures colder than one and two standard deviations below the mean (Fig. $3 \mathrm{~h}$ ).

Received 3 March 2014; accepted 22 July 2014; published online 17 August 2014

\section{References}

1. Stroeve, J. C. et al. Sea ice response to an extreme negative phase of the Arctic Oscillation during winter 2009/2010. Geophys. Res. Lett. 38, L02502 (2011).

2. Kwok, R. \& Rothrock, D. A. Decline in Arctic sea ice thickness from submarine and ICESat records: 1958-2008. Geophys. Res. Lett. 36, L15501 (2009).

3. Overland, J. E., Wang, M., Walsh, J. E. \& Stroeve, J. C. Future Arctic climate changes: adaptation and mitigation timescales. Earth's Future 2, 68-74 (2014)
4. Derksen, C. \& Brown, R. Spring snow cover extent reductions in the 2008-2012 period exceeding climate model projections. Geophys. Res. Lett. 39, L19504 (2012).

5. Matsumura, S., Zhang, X. \& Yamazaki, K. Summer Arctic atmospheric circulation response to spring Eurasian snow cover and its possible linkage to accelerated sea ice decrease. J. Clim. http://dx.doi.org/10.1175/ JCLI-D-13-00549.1 (2014).

6. Mudryk, L. R., Kushner, P. J. \& Derksen, C. Interpreting observed Northern Hemisphere snow trends with large ensembles of climate simulations. Clim. Dynam. 43, 345-359 (2013).

7. IPCC Summary for Policymakers in Climate Change 2013: The Physical Science Basis (eds Stocker, T. F. et al.) 3-29 (Cambridge Univ, Press, 2013).

8. Serreze, M. C., Barrett, A. P., Stroeve, J. C., Kindig, D. M. \& Holland, M. M. The emergence of surface-based Arctic amplification. Cryosphere 3, 11-19 (2009).

9. Screen, J. A. \& Simmonds, I. The central role of diminishing sea ice in recent Arctic temperature amplification. Nature 464, 1334-1337 (2010).

10. Cowtan, K. \& Way, R. G. Coverage bias in the HadCRUT4 temperature series and its impact on recent temperature trends. Q. J. R. Meteorol. Soc. 133, 459-77 (2013).

11. Holland, M. M. \& Bitz, C. M. Polar amplification of climate change in coupled models. Clim. Dynam. 21, 221-232 (2003).

12. Stroeve, J. C. et al. The Arctic's rapidly shrinking sea ice cover: a research synthesis. Climatic Change 110, 1005-1027 (2012).

13. Gillett, N. P. et al. Attribution of polar warming to human influence. Nature Geosci. 1, 750-754 (2008).

14. Winton, M. Amplified Arctic climate change: What does surface albedo feedback have to do with it? Geophys. Res. Lett. 33, L03701 (2006).

15. Serreze, M. C. \& Barry, R. G. Processes and impacts of Arctic amplification a research synthesis. Glob. Planet. Change 77, 85-96 (2011).

16. Screen, J. A., Deser, C. \& Simmonds, I. Local and remote controls on observed Arctic warming. Geophys. Res Lett. 39, L10709 (2012).

17. Shindell, D. \& Faluvegi, G. Climate response to regional radiative forcing during the twentieth century. Nature Geosci. 2, 294-300 (2009).

18. Francis, J. A. \& Hunter, E. New insight into the disappearing Arctic sea ice. EOS Trans. Am. Geophys. Union 87, 509-511 (2006).

19. Graverson, R. G. \& Wang, M. Polar amplification in a coupled climate model with locked albedo. Clim. Dynam. 33, 629-643 (2009).

20. Pithan, F. \& Mauritsen, T. Arctic amplification dominated by temperature feedbacks in contemporary climate models. Nature Geosci. 7, 181-184 (2014).

21. Graversen, R. G., Mauritsen, T., Tjernstrom, M., Kallen, E. \& Svensson, G. Vertical structure of recent Arctic warming. Nature 451, 53-56 (2008).

22. Wood, K. R. et al. Is there a "new normal" climate in the Beaufort Sea? Polar Res. 32, 19552 (2013).

23. Steele, M., Ermold, W. \& Zhang, J. Arctic Ocean surface warming trends over the past 100 years. Geophys. Res. Lett. 35, L19715 (2008)

24. Inoue, J. \& Hori, M. E. Arctic cyclogenesis at the marginal ice zone: A contributory mechanism for the temperature amplification? Geophys. Res. Lett. 38, L12502 (2011).

25. Screen, J. A. \& Simmonds, I. Increasing fall-winter energy loss from the Arctic Ocean and its role in Arctic amplification. Geophys. Res. Lett. 37, L16707 (2010)

26. Min, S. K., Zhang, X., Zwiers, F. W. \& Hegerl, G. C. Human contribution to more-intense precipitation extremes. Nature 470, 378-381 (2011).

27. Coumou, D. \& Rahmstorf, S. A decade of weather extremes. Nature Clim. Change 2, 491-496 (2012).

28. Westra, S., Alexander, L. V. \& Zwiers, F. W. Global increasing trends in annual maximum daily precipitation. J. Clim. 26, 3904-3918 (2013).

29. Coumou, D. \& Robinson, A. Historic and future increase in the global land area affected by monthly heat extremes. Environ. Res. Lett. 8, 034018 (2013).

30. Coumou, D., Robinson, A. \& Rahmstorf, S. Global increase in recordbreaking monthly-mean temperatures. Climatic Change 118, 771-782 (2013).

31. Seneviratne, S. I., Donat, M. G., Mueller, B. \& Alexander, L. V. No pause in the increase of hot temperature extremes. Nature Clim. Change 4, 161-163 (2014).

32. Donat, M. G. et al. Global land-based datasets for monitoring climatic extremes. Bull. Am. Meteorol. Soc. 94, 997-1006 (2013).

33. Screen, J. A. Arctic amplification decreases temperature variance in northern mid- to high-latitudes. Nature Clim. Change 4, 577-582 (2014).

34. Cohen, J., Barlow, M. \& Saito, K. Decadal fluctuations in planetary wave forcing modulate global warming in late boreal winter. J. Clim. 22, 4418-4426 (2009).

35. Liu, J., Curry, J. A., Wang, H., Song, M. \& Horton, R. Impact of declining Arctic sea ice on winter snow. Proc. Natl Acad. Sci. USA 109, 4074-4079 (2012).

36. Greene, C. H. \& Monger, B. C. An Arctic wild card in the weather. Oceanography 25, 7-9 (2012). 
37. Cohen, J., Furtado, J., Barlow, J. M., Alexeev, V. \& Cherry, J. Arctic warming, increasing fall snow cover and widespread boreal winter cooling. Environ. Res. Lett. 7, 014007 (2012).

38. Tang, Q., Zhang, X., Yang, X. \& Francis, J. A. Cold winter extremes in northern continents linked to Arctic sea ice loss. Environ. Res. Lett. 8, 014036 (2013).

39. Tollefson, J. US cold snap fuels climate debate. Nature http://dx.doi. org/10.1038/nature.2014.14485 (2014)

40. Hamilton, L. C. \& Lemcke-Stampone, M. Arctic warming and your weather: public belief in the connection. Int. J. Climatol. 34, 1723-1728 (2013).

41. Alexeev, V. A., Langen, P. L. \& Bates, J. R. Polar amplification of surface warming on an aquaplanet in "ghost forcing" experiments without sea ice feedbacks. Clim. Dynam. 24, 655-666 (2005).

42. Cohen, J., Furtado, J., Barlow, M., Alexeev, V. \&. Cherry, J. Asymmetric seasonal temperature trends. Geophys. Res. Lett. 39, L04705 (2012).

43. Wallace, J. M., Held, I. M., Thompson, D. W. J., Trenberth, K. E. \& Walsh, J. E. Global warming and winter weather. Science 343, 729-730 (2014).

44. Palmer, T. Record-breaking winters and global climate change. Science 344, 803-804 (2014).

45. Fischer, E. M. \& Knutti, R. Heated debate on cold weather. Nature Clim. Change 4, 577-582 (2014).

46. Cohen, J., Jones, J., Furtado, J. C. \&. Tziperman, E. Warm Arctic, cold continents: a common pattern related to Arctic sea ice melt, snow advance, and extreme winter weather. Oceanography 26, 150-160 (2013).

47. Vihma, T. Effects of Arctic sea ice decline on weather and climate: a review. Surv. Geophys. http://dx.doi.org/10.1007/s10712-014-9284-0 (2014).

48. Hoskins, B. The potential for skill across the range of the seamless weatherclimate prediction problem: a stimulus for our science. Q. J. R. Meteorol. Soc. 139, 573-584 (2013).

49. Woollings, T. \& Blackburn, M. The North Atlantic jet stream under climate change and its relation to the NAO and EA patterns. J. Clim 25, 886-902 (2012)

50. Bader, J. et al. A review on Northern Hemisphere sea-ice, storminess and the North Atlantic Oscillation: observations and projected changes. Atmos. Res. 101, 809-834 (2011).

51. Overland, J. E., Wood, K. R. \& Wang, M. Warm Arctic-cold continents: impacts of the newly open Arctic Sea. Polar Res. 30, 15787 (2011).

52. Wu, A., Hsieh, W. W., Boer, G. J. \& Zwiers, F. W. Changes in the Arctic Oscillation under increased atmospheric greenhouse gases. Geophys. Res. Lett 34, L12701 (2007)

53. Mote, T. \& Kutney, E. Regions of autumn Eurasian snow cover and associations with North American winter temperatures. Int. J. Climatol. 32, 1164-1177 (2012)

54. Cohen, J. \& Entekhabi, D. Eurasian snow cover variability and Northern Hemisphere climate predictability. Geophys. Res. Lett. 26, 345-348 (1999).

55. Cohen, J. \& Jones, J. A new index for more accurate winter predictions. Geophys. Res. Lett. 38, L21701 (2011).

56. Peings, Y., Brun, E., Mauvais, V. \& Douville, H. How stationary is the relationship between Siberian snow and Arctic Oscillation over the 20th century? Geophys. Res. Lett. 40, 183-188 (2013).

57. Brown, R. D. \& Derksen, C. Is Eurasian October snow cover extent increasing? Environ. Res. Lett. 8, 024006 (2013).

58. Ghatak, D., Frei, A., Gong, G., Stroeve, J. \& Robinson, D. On the emergence of an Arctic amplification signal in terrestrial Arctic snow extent. J. Geophys. Res. 115, D24105 (2010)

59. Ghatak, D. et al. Simulated Siberian snow cover response to observed Arctic sea ice loss, 1979-2008. J. Geophys. Res. 117, D23108 (2012).

60. Budikova, D. Role of Arctic sea ice in global atmospheric circulation. Glob. Planet. Change 68, 149-163 (2009).

61. Francis, J. A., Chan, W., Leathers, D. J., Miller, J. R. \& Veron, D. E. Winter Northern Hemisphere weather patterns remember summer Arctic sea-ice extent. Geophys. Res. Lett. 36, L07503 (2009).

62. Overland, J. E. \& Wang, M. Large-scale atmospheric circulation changes are associated with the recent loss of Arctic sea ice. Tellus A 62, 1-9 (2010).

63. Strong, C., Magnusdottir, G. \& Stern, H. Observed feedback between winter sea ice and the North Atlantic Oscillation. J. Clim. 22, 6021-6032 (2009).

64. Hopsch, S., Cohen, J. \& Dethloff, K. Analysis of a link between fall Arctic sea ice concentration and atmospheric patterns in the following winter. Tellus A 64, 18624 (2012).

65. Magnusdottir, G., Deser, C. \& Saravanan, R. The effects of North Atlantic SST and sea-ice anomalies on the winter circulation in CCM3. Part I: Main features and storm track characteristics of the response. J. Clim. 17, 857-876 (2004).

66. Deser, C., Magnusdottir, G., Saravanan, R. \& Phillips, A. The effects of North Atlantic SST and sea-ice anomalies on the winter circulation in CCM3. Part II: Direct and indirect components of the response. J. Clim. 17, 877-889 (2004).

67. Alexander, M. A. et al. The atmospheric response to realistic Arctic sea ice anomalies in an AGCM during winter. J. Clim. 17, 890-905 (2004).
68. Strey, S. T., Chapman, W. L. \& Walsh, J. E. The 2007 sea ice minimum: impacts on the Northern Hemisphere atmosphere in late autumn and early winter. J. Geophys. Res. 115, D23103 (2010).

69. Porter, D. F., Cassano, J. J. \& Serreze, M. C. Local and large-scale atmospheric responses to reduced Arctic sea ice and ocean warming in the WRF model. J. Geophys. Res. 117, D11115 (2012).

70. Bluthgen, J., Gerdes, R. \& Werner, M. Atmospheric response to the extreme Arctic sea ice conditions in 2007. Geophys. Res. Lett. 39, L02707 (2012).

71. Orsolini, Y., Senan, R., Benestad, R. \& Melsom, A. Autumn atmospheric response to the 2007 low Arctic sea ice extent in coupled ocean-atmosphere hindcasts. Clim. Dynam. 38, 2437-2448 (2012).

72. Singarayer, J. S., Valdes, P. J. \& Bamber, J. L. The atmospheric impact of uncertainties in recent Arctic sea-ice reconstructions. J. Clim. 18, 3996-4012 (2005)

73. Screen, J. A., Deser, C., Simmonds, I. \& Tomas, R. Atmospheric impacts of Arctic sea-ice loss, 1979-2009: separating forced change from atmospheric internal variability. Clim. Dynam. 43, 333-344 (2013).

74. Peings, Y. \& Magnusdottir, G. Response of the wintertime Northern Hemispheric atmospheric circulation to current and projected Arctic sea ice decline: a numerical study with CAM5. J. Clim. 27, 244-264 (2014).

75. Tanaka, H. L. \& Seki, S. Development of a three-dimensional spectral linear baroclinic model and its application to the baroclinic instability associated with positive and negative Arctic Oscillation indices. J. Meteorol. Soc. Jpn 91, 193-213 (2013).

76. Francis, J. A. \& Vavrus, S. J. Evidence linking Arctic amplification to extreme weather in mid-latitudes. Geophys. Res. Lett. 39, L06801 (2012)

77. Petoukhov, V., Rahmstorf, S., Petri, S. \& Schellnhuber, H. J. Quasiresonant amplification of planetary waves and recent Northern Hemisphere weather extremes. Proc. Natl Acad. Sci. USA 110, 5336-5341 (2013).

78. Screen, J. A. \& Simmonds, I. Amplified mid-latitude planetary waves favour particular regional weather extremes. Nature Clim. Change http://dx.doi. org/10.1038/nclimate2271 (2014).

79. Barnes, E. A. Revisiting the evidence linking Arctic amplification to extreme weather in midlatitudes. Geophys. Res. Lett. 40, 1-6 (2013).

80. Allen, R. J. \& Sherwood, S. C. Warming maximum in the tropical upper troposphere deduced from thermal winds. Nature Geosci. 1, 399-403 (2008).

81. Screen, J. A. \& Simmonds, I. Exploring links between Arctic amplification and mid-latitude weather. Geophys. Res. Lett. 40, 959-964 (2013).

82. Barnes, E. A., Dunn-Sigouin, E., Masato, G. \& Woollings, T. Exploring recent trends in Northern Hemisphere blocking. Geophys. Res. Lett. 41, 638-644 (2014).

83. Kintisch, E. Into the maelstrom. Science 344, 250-253 (2014)

84. Fletcher, C., Hardiman, S. C., Kushner, P. J. \& Cohen, J. The dynamical response to snow cover perturbations in a large ensemble of atmospheric GCM integrations. J. Clim. 22, 1208-1222 (2009).

85. Allen, R. J. \& Zender, C. S. Forcing of the Arctic Oscillation by Eurasian snow cover. J. Clim. 24, 6528-6539 (2011)

86. Cohen, J., Furtado, J. C., Jones, J., Barlow, M., Whittleston, D. \& Entekhabi, D. Linking Siberian snow cover to precursors of stratospheric variability. J. Clim. 27, 5422-5432 (2014)

87. Peings Y., Saint-Martin, D. \& Douville, H. A numerical sensitivity study of the influence of Siberian snow on the northern annular mode. J. Clim 25, 592-607 (2012).

88. Petoukhov, V. \& Semenov, V. A. A link between reduced Barents-Kara sea ice and cold winter extremes over northern continents. J. Geophys. Res. 115, D21111 (2010).

89. Inoue, J., Hori, M. E. \& Takaya, K. The role of Barents Sea ice in the wintertime cyclone track and emergence of a warm-Arctic cold-Siberian anomaly. J. Clim. 25, 2561-2568 (2012).

90. Jaiser, R., Dethloff, K., Handorf, D., Rinke, A. \& Cohen, J. Impact of sea ice cover changes on the Northern Hemisphere atmospheric winter circulation. Tellus A 64, 11595 (2012).

91. Jaiser, R., Dethloff, K. \& Handorf, D. Stratospheric response to Arctic sea ice retreat and associated planetary wave propagation changes. Tellus $A$ 65, 19375 (2013)

92. Honda, M., Inue, J. \& Yamane, S. Influence of low Arctic sea-ice minima on anomalously cold Eurasian winters. Geophys. Res. Lett. 36, L08707 (2009).

93. Hardiman, S. C., Kushner, P. J. \& Cohen, J. Investigating the ability of general circulation models to capture the effects of Eurasian snow cover on winter climate. J. Geophys. Res. 113, D21123 (2008).

94. Martin, S. \& Diffenbaugh, N. S. Transient twenty-first century changes in daily-scale temperature extremes in the United States. Clim. Dynam. 42, 1383-1404 (2014).

95. Dee, D. P. et al. The ERA-Interim reanalysis: configuration and performance of the data assimilation system. Q. J. R. Meteorol. Soc. 137, 553-597 (2011).

96. Hansen, J. E. \& Lebedeff, S. Global trends of measured surface air temperature J. Geophys. Res. 92, 13345-13372 (1987). 
97. Hoskins, B. J. \& Karoly, D. J. The steady linear response of a spherical atmosphere to thermal and orographic forcing. J. Atmos. Sci. 38, 1179-1196 (1981).

98. Garfinkel, C. I., Hartmann, D. L. \& Sassi, F. Tropospheric precursors of anomalous Northern Hemisphere stratospheric polar cortices. J. Clim. 23, 3282-3299 (2010).

99. Kolstad, E. W. \& Charlton-Perez, A. J. Observed and simulated precursors of stratospheric polar vortex anomalies in the Northern Hemisphere. Clim. Dynam. 37, 1443-1456 (2010).

100. Cohen, J. \& Jones, J. Tropospheric precursors and stratospheric warmings. J. Clim. 24, 6562-6572 (2011).

\section{Acknowledgements}

We are grateful to E. Barnes for many helpful discussions and suggested revisions to the manuscript. J.C. is supported by the National Science Foundation grants BCS-1060323 and AGS-1303647. J.S. is funded by Natural Environment Research Council grant NE/J019585/1. M.B. received support from National Science Foundation grant
ARC-0909272 and NASA NNX13AN36G. J.O. receives support from the Arctic Research Project of the National Oceanic and Atmospheric Administration Climate Program Office and the Office of Naval Research, Code 322.

\section{Author contributions}

J.C. proposed and was the main author of the manuscript. All co-authors contributed to the writing of the manuscript. J.S. created Fig. 1, J.F. Figs $2 \& 4$, D.C. Fig. 3, J.F. and J.C. Fig. 4, M.B. and J.C. Fig. B1, and D.W. and J.C. Fig. B2.

\section{Additional information}

Supplementary information accompanies this paper on www.nature.com/ngeo. Reprints and permissions information is available online at www.nature.com/reprints. Correspondence and requests for materials should be addressed to J.C.

\section{Competing financial interests}

The authors declare no competing financial interests. 